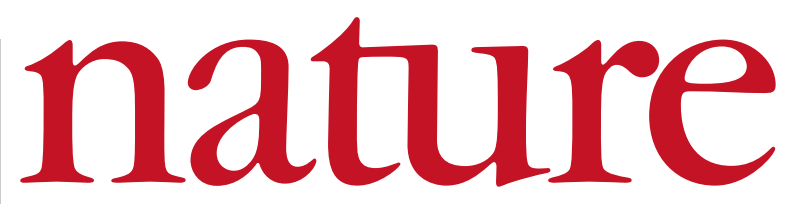

28 October 2004 Volume 431 Issue no 7012

\title{
Struggling with the flu
}

The shortages of flu vaccine in the United States this autumn have laid bare some troubling weaknesses in the nation's public-health system.

$\mathrm{T}$ his month, the United States has been experiencing a publichealth fiasco about which government officials had been repeatedly forewarned.

Since the anthrax attacks of 2001, health experts have been highlighting the weak condition of the nation's system for purchasing and distributing vaccines against potential bioterror agents. But this autumn's shortage of flu vaccine - triggered when British regulators found contamination in vaccine from a plant in Liverpool that was supposed to supply half of it — graphically demonstrates their point.

The flu vaccine is tricky to produce, because it must be grown in chicken eggs months in advance. But that is not the root of the problem. As an Institute of Medicine report expressed it last year: "The public-private partnership that has formed the foundation for purchasing and distributing vaccines over the past 50 years is showing signs of erosion."

The United States relies on private companies to make flu vaccine, many of which have decided that they could better serve their stockholders by making blockbuster drugs that boost sex drive or cut high blood pressure. Unlike Canada or Britain, the United States also relies on the private sector to distribute flu vaccines at grocery stores, pharmacies and doctors' surgeries.

As a result, according to an official from the Government Accountability Office who testified at Congress last month: "There is no system in place to ensure that seniors and others at high risk for complications receive flu vaccinations first when vaccine is in short supply." This was demonstrated all too vividly last week, when a 79-year-old Californian woman stumbled and died after having to queue for four hours for the vaccine in a grocery-store parking lot.

President Bush has been trying to shift the blame on to trial lawyers, claiming on the campaign trail that excessive legal liability has deterred drug companies from making vaccines. But that isn't why they have stepped away from producing vaccines; the real reasons are low profit margins and a lack of reliable demand.

In July, Bush signed the Project Bioshield Act, which is supposed to lift the obstacles that prevent drug companies from developing the medicines needed to defend against biological attack. But it isn't clear that the Department of Homeland Security, which sets the priorities for Project Bioshield, regards flu as falling under its domain.

The Department of Health and Human Services, under the leadership of health secretary Tommy Thompson and the supervision of Congress, has failed to take steps to ensure a steady demand for flu vaccine, or guarantee a price for it. It could have responded to previous warnings and issued an estimate for the number of vaccines that the nation would need in the coming year, while promising to purchase any remaining doses of the vaccine. It could also have made sure that every state had a plan for dealing with a vaccine shortage. And it could have helped to develop cell-culture techniques for fluvaccine production as alternatives to the chicken eggs.

A mixture of ideological opposition and bureaucratic sclerosis has forestalled these actions. And, strikingly, three years of heightened concern about bioterrorism have done nothing to address the fundamental weakness of the US public-health system. Whether the threat is bioterror or flu, the lack of robustness in that system has never been more apparent.

\section{Fishing for excuses}

The message from researchers about the state of European fish stocks is consistent, but its delivery could be improved.

$t$ is the same procedure every year: based on the advice of fisheries biologists across Europe, the International Council for the Exploration of the Sea (ICES) has again recommended a ban on cod fishing in the North Sea, the Irish Sea and west of Scotland.

As usual, the advice is likely to fuel a public outcry in the regions where fishermen live. And the European Union (EU), which sets annual catch quotas for fish, must walk a fine line between conserving the short-term future of the fisheries industry and the long-term survival of fish stocks. This annual event has already driven a wedge between scientists and fishing communities, a bad starting point for addressing the problem of fisheries conservation. Not only do fishing communities tend to dig in their heels, but conservationists sometimes exaggerate the need for draconian reductions in quotas.

Marine biologists often disagree over the best ways to conserve declining fish stocks worldwide (see Nature 419, 662-665; 2002). And it isn't certain that fishing for threatened species — such as European cod - has to stop entirely, if stocks are to recover. This year, for example, cod stocks in the North Sea appear to have bounced back up by almost one-third, albeit from a worryingly low estimate of 35,000 tonnes, despite the fact that some fishing is permitted. ICES thinks that no fishing should be allowed until stocks reach 150,000 tonnes.

But fish population dynamics is an uncertain business. Biologists' models don't work well if the stock in question is small, as is the case with European cod. Fish populations can fluctuate enormously from one generation to the next, depending on environmental conditions such as the weather, ocean turbulence and plankton availability. If the hydrographical conditions are favourable next season, cod stocks may recover further - but they could just as easily collapse. So from a precautionary point of view, it is understandable that scientists recommend fishing bans, even though they don't know for sure that continued fishing will wipe out European cod.

Such uncertainty does not release the EU from its obligation to optimize fisheries management. It can't do much about sea temperatures and ocean currents, but it can set sensible quotas on catches.

It probably makes sense that these quotas allow some cod fishing to continue, while reducing national fishing fleets and restricting the number of days that vessels are allowed at sea. Scientists can contribute to this process by acknowledging the uncertainties in their work. But it falls to fisheries managers and political leaders to persuade fishermen that quotas are fair and necessary. 